\title{
Ensino de ética jornalística: pedagogias e metodologias de professores $^{1}$
}

\author{
Rogério Christofoletti \\ Doutor, professor e pesquisador do Departamento de Jornalismo da Universidade Federal de \\ Santa Catarina (UFSC). \\ E-mail: rogerio.christofoletti@uol.com.br
}

Resumo: $\mathrm{O}$ ensino de ética no jornalismo é pouco estudado e ainda insuficientemente discutido no Brasil. De fato, este cenário não é exclusividade do Jornalismo. Neste artigo, são os professores das disciplinas de ética jornalística quem fornecem dados importantes sobre como se ensina deontologia nos cursos superiores da área no país. O estudo se apoia numa amostra dos cem cursos brasileiros mais tradicionais, e os professores responderam a um questionário onde apontam como baseiam suas práticas pedagógicas, que metodologias e tecnologias utilizam. Os resultados sugerem que, embora onipresente, o ensino de ética jornalística ainda carece consolidar conteúdos e abordagens. Apontam também para esforços dos docentes para dinamizar as aulas.

Palavras-chave: Ética Jornalística, Ensino de Jornalismo, Pedagogia, Comunicação, Educação.
Abstract: The teaching of ethics in journalism is rarely studied and discussed in Brazil. This scenario is not unique to journalism. In this work, professors of ethics provide important information about how to teach ethics in journalism courses in the country. We use a sample of one hundred more traditional courses and teachers responded to a questionnaire about teaching practices, methodologies and technologies used. The results suggest that, although ubiquitous, the teaching of journalistic ethics has yet to consolidate content and approaches. The data also point to efforts to boost teachers' classes.

Keywords: Journalistic Ethics, Journalism Education, Pedagogy, Communication, Education.

O ensino superior reserva problemáticas que extrapolam os limites da sala de aula, já que os resultados dos esforços ali empreendidos se refletem nas relações a serem estabelecidas entre os profissionais recém-formados e a sociedade em geral. Este ensino reserva para si não apenas a preparação para o mercado de trabalho, mas também auxilia na formação de cidadãos executores de tarefas complexas, empreendedores em diversas áreas e novas lideranças sociais e profissionais. Há carreiras em que essa formação é um processo delicado, estratégico e fundamental, como no caso do jornalismo.

1. Este artigo apresenta resultados parciais da pesquisa Ensino de Deontologia nos cursos superiores de Jornalismo no Brasil: pedagogias, metodologias e tecnologias, financiada com recursos do Edital Universal 2008 do CNPq. 
2. A proporção da amostra é: $56 \%$ da região Sudeste, $24 \%$ do Sul, $12 \%$ do Nordeste, 7\% do Centro-Oeste e 1\% do Norte.

3. CHRISTOFOLETTI, Rogério. Pesquisa: Ensino de Ética Jornalística. Disponível em: <http://spreadsheets.google.com/vie wform? formkey $=$ cEE3WU FaTEIHUXVWQjIKRC1pY2 dWTEE6MA >. Acesso em: 9 jun. 2010. Questionário eletrônico.

4. Conforme as normas da Comissão Nacional de Ética em Pesquisa (Conep). Resolução n. 196/1996.
Por isso, formar novos jornalistas implica não apenas satisfazer demandas mercadológicas, mas um imaginário político-social - em que jornalistas e meios desempenham papéis de fiscalização dos poderes, por exemplo - também precisa ser satisfeito. É comum associar modelos de sociedades plenamente desenvolvidas a uma imprensa atuante e movida por profissionais capazes e envolvidos. Mas sobram questões sobre o ensino de jornalismo em geral, e de ética profissional em particular: é possível ensiná-la nos cursos? Como são preparados novos jornalistas, quando o assunto é ética? Os professores estão plenamente capacitados para isso? Que recursos utilizam?

\section{PROCEDIMENTOS METODOLÓGICOS}

Para responder, recorremos a um conjunto de técnicas de pesquisa que permitiram maior acesso a informações. Inicialmente, buscamos identificar as disciplinas que contribuem para a dimensão deontológica da formação dos jornalistas. Como há imprecisões até mesmo na Secretaria de Ensino Superior do Ministério da Educação, optamos por uma amostra do universo de mais de mil ofertas em Comunicação, das quais mais de trezentas são em Jornalismo. Fechamos a amostra nos cem cursos mais antigos da carreira, de maneira a compor uma amostra abrangente, equilibrada e representativa da realidade do ensino de Jornalismo no Brasil. As características da população são: os cursos surgiram entre 1947 e 1999; estão em 19 unidades da federação, de todas as regiões $^{2}$; são cursos instalados em faculdades, universidades e centros universitários municipais, estaduais e federais, em instituições públicas e particulares.

A partir da amostra, foram obtidos currículos, ementários e planos de ensino das disciplinas, que possibilitaram natureza, presença, duração e especificidades das matérias ético-profissionais. Entre a população da pesquisa, apenas um curso não oferece disciplinas que tratem dessa dimensão formativa, fato que demonstra um interesse quase consensual da necessidade de contemplar tais conteúdos nos currículos. Foi ainda percebido que é comum os cursos vincularem deontologia, ética e legislação, e que às vezes as disciplinas oscilam entre os campos da Comunicação, do Jornalismo, da Filosofia e do Direito.

Tendo em vista que esses documentos apenas sinalizam proposições e planejamentos pedagógicos, e que são dinâmicos os processos e o cotidiano de sala de aula, a pesquisa partiu para outra técnica: entrevistar os professores das disciplinas de forma a ter acesso a metodologias, pedagogias e tecnologias aplicadas ao ensino de ética jornalística. Foi mantida a amostra do estudo, e as coordenações dos cem cursos foram contatadas, informando a realização da pesquisa e solicitando os nomes e e-mails pessoais dos professores responsáveis pelas disciplinas.

Uma mensagem eletrônica foi encaminhada aos professores, explicando os objetivos da pesquisa e convidando a participarem dela. No segundo contato, foi enviado link com a direção de um questionário eletrônico ${ }^{3}$, garantindo-se o anonimato e a confidencialidade das informações ${ }^{4}$. O questionário continha 18 
questões, sendo 15 de múltipla escolha e três discursivas. O questionário ficou disponível para preenchimento entre maio e junho de 2009, e 35 professores responderam.

\section{ÉTICA JORNALÍSTICA SOB O VIÉS DO ENSINO}

O questionário respondido pelos professores mesclou questões discursivas e de múltipla escolha, e elas buscavam respostas que podem ser enquadradas em quatro aspectos: caracterização da disciplina e dos professores; relação entre a disciplina e a formação dos jornalistas; aspectos pedagógicos; e tecnologias aplicadas à disciplina pelos docentes.

\section{AS DISCIPLINAS E OS PROFESSORES}

A primeira questão perguntava sobre o título da disciplina sobre ética lecionada. Mais da metade dos sujeitos da pesquisa (56\%) assinalou as alternativas Legislação e Ética em Jornalismo ou sua variante Ética e Legislação em Jornalismo, 9\% responderam ser Ética Jornalística, 6\%, Ética e Cidadania, e 3\%, Ética. Mais de um quarto dos respondentes (26\%) marcou Outra. Duas conclusões iniciais: a) na maioria dos casos, conteúdos de deontologia são oferecidos junto com os de legislação na área; b) há grande diversidade na nomenclatura das disciplinas deste tipo, já que a forte presença da alternativa Outra sinaliza a pulverização de respostas possíveis.

Tendo-se observado nos currículos dos cursos a proximidade e, em alguns casos, a intercessão entre legislação e ética, foi perguntado aos sujeitos da pesquisa em que proporção deveriam ser oferecidos os conteúdos de uma área e outra. As respostas mostraram não haver uma preocupação com isso: $35 \%$ afirmaram meio a meio e juntos; $21 \%$, meio a meio e separados; $32 \%$ marcaram a alternativa mais ética e deontologia; $1 \%$, mais direito e legislação, e 2\%, assinalaram pouco importa a proporção, mais importante é que sejam oferecidos juntos. Note-se que $62 \%$ dos docentes consideram que conteúdos de Ética e de Legislação devem ser ensinados juntos, e menos de um terço prefere que haja predomínio de conteúdos reflexivos e deontológicos. Essa posição contraria argumentos como os de Cheida (2007) ${ }^{5}$, Gentilli (2001) ${ }^{6}$, Christofoletti (2007; 2009) ${ }^{7}$ e Karam $(1997)^{8}$, que advogam disciplinas mais específicas.

A caracterização dos docentes que responderam à pesquisa auxilia a visualizar um perfil dos professores de ética jornalística. Majoritariamente, têm formação na área - em Comunicação ou Jornalismo - (66\%) e são experientes, lecionando a disciplina há mais de cinco anos (51\%). 14\% dos docentes afirmaram ter graduações em Direito ou Filosofia - o que ajudaria a explicar por que em alguns casos as disciplinas se limitam a aspectos jurídicos ou à história das correntes filosóficas; 3\% são formados em Teologia ou Letras e $17 \%$ têm outras formações.
5. CHEIDA, Marcelo. A questão curricular e pedagógica na disciplina Ética e Legislação em Jornalismo. REBEJ: Revista Brasileira de Ensino de Jornalismo, Brasília, v. 1, n. 1, p. 157-177, abr./ jul. 2007.

6. GENTILLI, Victor. Lei, ética e deontologia. Observatório da Imprensa, n. 132, 1 ago. 2001. Disponível em: <http:// observatorio.ultimosegundo.ig.com.br/artigos/ da010820011.htm>. Acesso em: 2 maio 2010.

7. CHRISTOFOLETTI, Rogério. Dez propostas para o ensino de ética jornalística no Brasil. Disponível em: <http:// www.fnpj.org.br/noticias. php?act=listar \&cod=422>. Acesso em: 15 maio 2010; Formação ético-profissional: presença e evolução nos currículos de um curso de Jornalismo. XII Encontro $\mathrm{Na-}$ cional de Professores de Jornalismo. Belo Horizonte, 2009. Disponível em: <http://www.fnpj. org.br/soac/ocs/viewpaper. $p h p$ ? id=603\&cf=18>. Acesso em: 20 abr. 2010.

8. KARAM, Francisco José. Jornalismo, ética e liberdade. São Paulo: Summus, 1997. 
comunicação \& educação • Ano XVI • número 1 • jan/jun 2011

\section{DISCIPLINAS DEONTOLÓGICAS E A FORMAÇÃO DOS JORNALISTAS}

Sete perguntas trataram da relação entre as disciplinas ético-profissionais e a formação geral dos jornalistas. Sobre a importância da matéria, $70 \%$ responderam ser muito relevante; $15 \%$, ser a mais relevante do curso; e outros $15 \%$ a consideram relevante. As alternativas pouco relevante e descartável foram ignoradas e não tiveram nenhuma resposta.

Mercado e academia se conjugam e se chocam nas disciplinas deontológicas. Os resultados foram bem fracionados no que tange à relação dessas matérias com os mundos da escola e do trabalho. Para $42 \%$ dos consultados, a disciplina de ética, sua presença no currículo e sua ementa ressaltam aspectos mais acadêmicos e teóricos na formação dos novos jornalistas; para um terço dos sujeitos, a matéria aproximam mercado e academia; para 15\%, contrapõem mercado e academia; e para $9 \%$, salientam um caráter mais mercadológico e profissional na formação dos novos jornalistas.

A presença de conteúdos ético-profissionais nos currículos foi considerada suficiente e em boa dose para $68 \%$ dos docentes. Os professores se dividem mais quando o assunto é a bibliografia de ética jornalística: para $47 \%$ dos entrevistados, ela é suficiente para a disciplina; para 32\%, parcialmente; e 21\% consideram a bibliografia deficiente.

Embora se perceba nos currículos a oferta frequente de disciplinas que mesclem conteúdos de ética, deontologia e legislação, os docentes - na maioria das vezes $(82 \%)$ - reconhecem diferenças significativas entre essas áreas. Uma parcela de $12 \%$ não vê distinções, enquanto $6 \%$ afirmam não se importarem com isso. A consciência das distinções - expressa nesta questão - e a preferência pela oferta dos conteúdos conjugados desses saberes - demonstrada anteriormente - reforçam pouca resistência na aproximação entre legislação, ética e deontologia. Essa posição ajuda a explicar a natureza porosa de algumas disciplinas e a heterogeneidade de seus conteúdos.

Quando questionados sobre que conteúdos ou temas não constam de suas disciplinas e seriam bem-vindos, alguns docentes queixaram-se mais da carga horária que têm à disposição do que das ementas das matérias. Segundo as respostas abertas, em muitos casos, há tempo insuficiente para incluir novos tópicos de ensino e mesmo para aprofundar os já existentes nos planos de aula. O fator tempo é impeditivo de mais flexibilidade e mais mobilidade nas disciplinas.

Alguns respondentes sugeriram que conteúdos de uma História Moral do Jornalismo e que articulassem avanços tecnológicos e implicações éticas no cotidiano pudessem compor as ementas de suas disciplinas. Um docente foi além, propondo que a disciplina de ética fosse desdobrada ao longo de mais semestres, a exemplo do que se faz com algumas matérias de base, como Língua Portuguesa ou Redação. A preocupação do respondente é com a capacitação teórica $e$ pedagógica de alguns professores em relação a conteúdos referentes à ética. Acreditando haver dilemas próprios de alguns meios, o respondente sugere a inclusão nos 
currículos de disciplinas complementares de Ética em Radiojornalismo, Ética em Telejornalismo etc.

\section{A DISCIPLINA E O PROFESSOR EM SALA DE AULA}

O questionário respondido continha ao menos quatro perguntas que permitiram entrever as escolhas pedagógicas dos docentes para ministrar as disciplinas deontológicas nos cursos. A primeira delas indagava sobre quais dinâmicas são usadas em sala de aula. No formato de múltipla escolha e podendo ser marcada mais de uma alternativa, a pergunta apresentou os seguintes resultados: $86 \%$ dos docentes usam leituras e discussões teóricas para ensinar ética jornalística; $77 \%$ lançam mão de estudos de casos; $74 \%$ se apoiam em aulas expositivas; $51 \%$ organizam e conduzem debates e julgamentos; $49 \%$ afirmam orientar suas aulas pelo ensino baseado em problemas; $11 \%$ recorrem a teatro, dramatização e vivências. Uma fatia de $20 \%$ dos respondentes marcou a opção Outros. O fracionamento das escolhas mostra que os professores não se apoiam em apenas uma técnica de ensino e que oscilam entre uma didática mais escolástica, elementar e conservadora - cuspe e giz, como diz o jargão - e experiências pedagógicas mais ousadas, criativas e inovadoras. Não existe um padrão único, exceto pelo fato de que o docente parece não se acomodar num terreno estabilizado, buscando constantemente dinamizar suas aulas.

Reforçam esse perfil as respostas à questão sobre a linha ou corrente pedagógica em que o docente pensa se enquadrar. Abertas, as respostas foram: da Pedagogia Renovada à Libertadora, do Construtivismo ao Marxismo com a assunção de pressupostos do Pós-Estruturalismo, do Sociointeracionismo a um viés teórico-prático. Foram registradas respostas de docentes que não sabem se encaixar pedagogicamente ou que não conseguem fazê-lo. Este resultado é natural vindo de professores de Jornalismo - graduação do tipo bacharelado -, e muitas vezes sem capacitação formal para lecionar ${ }^{9}$.

Essa insegurança emerge sorrateira nas respostas à questão que trata de como o docente se avalia na disciplina. Embora a maioria considere-se preparada tanto nos conteúdos quanto pedagogicamente $(62 \%)$, chama a atenção a parcela de $29 \%$, que gostaria de ter uma capacitação pedagógica, e a fatia de $1 \%$, que se sinta totalmente inseguro. Somados, representam quase um terço dos sujeitos da pesquisa, e conscientemente fragilizados num aspecto estratégico do processo de ensino-aprendizagem: o professor domina o conteúdo, mas não se sente plenamente capaz de ministrá-lo. É uma situação mais grave que a dos que se consideram bem preparados pedagogicamente, mas estejam inseguros quanto aos conteúdos $(6 \%)$. Afinal, uma reciclagem ou atualização profissional podem dar conta desses casos.

O questionário indagava ao professor qual a maior dificuldade ao lecionar as disciplinas ético-profissionais. Era facultado assinalar mais de uma opção. A maior parcela (47\%) afirmou não ter dificuldades, mas este percentual nem sequer chega à metade dos sujeitos da pesquisa, o que permite inferir que os
9. É preciso reconhecer ainda que a maioria dos cursos de pós-graduação em Comunicação não oferece disciplinas voltadas à didática do ensino superior. 
comunicação \& educação • Ano XVI • número 1 • jan/jun 2011

professores não estejam tão preparados pedagogicamente quanto assinalaram em questões anteriores. As demais alternativas foram assim marcadas: $21 \%$ sentem necessidade de uma didática própria para essas aulas; $15 \%$ dizem que a bibliografia é escassa ou inacessível; $15 \%$ queixam-se dos poucos materiais de apoio à disciplina; $12 \%$ afirmam desconhecer literatura específica sobre ensino de ética que pudesse auxiliar; para 9\%, a natureza da disciplina restringe o ensino a abordagens muito escolásticas e convencionais; para $1 \%$, os temas são áridos e complexos demais, o que dificulta explorações mais aprofundadas. Uma parcela de 15\% assinala haver Outras dificuldades ao lecionar tais disciplinas.

Esta pesquisa não permite dimensionar qual o alcance dos problemas didático-pedagógicos existentes no cotidiano dos professores de Jornalismo nas disciplinas ético-profissionais, mas as respostas colhidas no questionário evidenciam que há gargalos que podem dificultar esse ensino e, em casos mais graves, até comprometer a formação.

\section{TECNOLOGIAS APLICADAS À PEDAGOGIA}

A abordagem aos docentes abrangia ainda cotejar tecnologias educacionais e ensino deontológico. Três questões tratavam disso. Na primeira, era questionado ser possível lecionar tais conteúdos com recursos tecnológicos. A esmagadora maioria respondeu afirmativamente (97\%). Considerar que se possa lecionar tais conteúdos com recursos tecnológicos não significa necessariamente que esses dispositivos sejam imprescindíveis para o ensino. É o que demonstram os resultados da questão que inquiria se tecnologia era um fator importante para essas matérias. A vigorosa resposta anterior fragmentou-se: $45 \%$ assinalaram mais ou menos; $42 \%$ marcaram sim e $12 \%$ responderam não.

Verificou-se uma nova pulverização de respostas diante da questão sobre os recursos tecnológicos usados nas disciplinas deontológicas. Sob o formato de múltipla escolha, a pergunta permitia assinalar mais de uma alternativa, caso o respondente assim o quisesse. A distribuição das respostas e sua heterogeneidade reforçam a disposição dos docentes em dinamizar suas aulas: $82 \%$ afirmam usar filmes em vídeo; $65 \%$ lançam mão de apresentações multimídia (PowerPoint, por exemplo); $53 \%$ disseram recorrer a blogs ou sites especificos; $32 \%$ usam retroprojetores; $21 \%$ apoiam-se em ambientes virtuais de aprendizagem; $6 \%$ utilizam lousa digital; outros $6 \%$ assinalaram chats e fóruns; $3 \%$, sites de relacionamento; $3 \%$, outros recursos; $6 \%$ afirmaram não usar nenhum daqueles recursos.

Conflitantes, as respostas sobre a presença e o papel da tecnologia no ensino de ética jornalística mostram menos um problema central e mais uma questão periférica. Os professores não chegam a ser resistentes ao uso de recursos e até lançam mão a variados tipos - dos quase obsoletos retroprojetores a sites de relacionamento. Os docentes admitem que a tecnologia possa auxiliar, mas ela não parece ser condição sine qua non para uma formação efetiva e eficaz nesta dimensão. 


\section{CONSIDERAÇÕES FINAIS}

Os resultados colhidos nos questionários preenchidos pelos docentes são esclarecedores, embora não permitam conclusões muito definitivas de como o ensino de ética jornalística se configura no país. Isso se deve à própria complexidade da temática - o ensino do jornalismo em geral e o ensino de ética jornalística em particular - e à necessidade de mais abordagens investigativas ao objeto. No entanto, algumas considerações podem ser extraídas do material coletado.

De imediato, percebe-se que, na encruzilhada do ensino de conteúdos ético-profissionais nos cursos brasileiros de Jornalismo, a tecnologia não é um problema; é uma possibilidade. Os docentes não temem ferramentas e recursos, e chegam a lançar mão de muitos deles. Mais delicado é o caso das metodologias empregadas e das pedagogias de suporte. Os dados das entrevistas permitem afirmar que não se chegou a consolidar um método de ensino de ética jornalística. Várias razões podem ajudar a justificar essa condição: a escola brasileira tem pouco mais de 40 anos e é relativamente recente, o conhecimento da área é dinâmico e mutante, e os próprios docentes ainda não amadureceram pedagogicamente, se comparados a outros campos do saber, mais estabilizados.

Note-se, por exemplo, que embora o Brasil conte com 39 programas de pós-graduação ${ }^{10}$, são raros os casos em que são oferecidas disciplinas que possam reforçar a formação de novos docentes na área, como Didática de Ensino Superior e Ensino de Comunicação, por exemplo. Também não é nítida no âmbito da pós-graduação da área a presença de linhas de pesquisa que se dediquem mais concentradamente na investigação de métodos, didáticas e abordagens pedagógicas para os cursos de Comunicação.

Sem clareza de alguns fundamentos da Educação, carentes de instrução formal para o magistério superior e vivendo numa cultura ainda incipiente de debate pedagógico na área, os professores de jornalismo fragilizam seu papel na formação dos novos profissionais que vão movimentar as redações dos meios de comunicação e as agências de comunicação. Some-se a isso o fato de que a dimensão ético-profissional não assume papel central na formação dos novos profissionais, ao menos pelo que se percebe pelas respostas colhidas nos questionários da pesquisa: as disciplinas são híbridas, muitas vezes não contagiam outras matérias, têm duração limitadora e mesclam seus conteúdos com saberes de outras áreas, diluindo a ênfase na discussão de dilemas éticos e situações de tomada de decisão na profissão.

Fragilizado, o ensino de ética jornalística apenas é enfatizado na retórica dos cursos e não em seus currículos, ementários ou projetos pedagógicos. Ruim para a Educação, ruim para o Jornalismo, mas muito pior para a sociedade a quem os jornalistas devem servir e atender os interesses.

Como a educação é um processo e como a evolução do ensino é uma resultante de movimentos endógenos e exógenos às escolas, resta a esperança de que o ensino de jornalismo, em geral, e o de deontologia jornalística, em
10. São 24 programas com Mestrado e $15 \mathrm{com}$ Mestrado e Doutorado, conforme levantamento da Associação Nacional dos Programas de Pós-Graduação em Comunicação (Compós). 
comunicação \& educação • Ano XVI • número 1 • jan/jun 2011

específico, desenvolvam-se com bases pedagógicas fortes e com eixos bem orientados.

\section{REFERÊNCIAS BIBLIOGRÁFICAS}

CHEIDA, Marcelo. A questão curricular e pedagógica na disciplina Ética e Legislação em Jornalismo. REBEJ: Revista Brasileira de Ensino de Jornalismo, Brasília, v. 1, n. 1, p. 157-177, abr./jul. 2007.

KARAM, Francisco José. Jornalismo, ética e liberdade. São Paulo: Summus, 1997.

\section{Endereços eletrônicos}

GENTILLI, Victor. Lei, Ética e Deontologia. Observatório da Imprensa, n. 132, 1 ago. 2001. Disponível em <http://observatorio.ultimosegundo.ig.com.br/ artigos/da010820011.htm>. Acesso em: 2 maio 2010.

CHRISTOFOLETTI, Rogério. Dez propostas para o ensino de ética jornalística no Brasil. Disponível em: <http://www.fnpj.org.br/noticias. php?act=listar\&cod=422>. Acesso em: 15 maio 2010.

Formação ético-profissional: presença e evolução nos currículos de um curso de Jornalismo. XII Encontro Nacional de Professores de Jornalismo. Belo Horizonte: 2009. Disponível em: <http://www.fnpj.org.br/soac/ocs/viewpaper. php?id=603\&cf=18>. Acesso em: 20 abr. 2010.

.Pesquisa: Ensino de Ética Jornalística. Disponível em: $<$ http:/ / spreadsheets. google.com/viewform?formkey=cEE3WUFaTElHUXVWQjlKRC1pY2dWTEE6 MA>. Acesso em: 9 jun. 2010. Questionário eletrônico. 